\title{
EL ARTE DE LA MEMORIA EN UNA BELLEZA CONVULSA DE J. M. FAJARDO
}

\author{
$\mathrm{M}^{\mathrm{a}}$ DOLORES ALONSO REY ${ }^{1}$
}

Universidad de Angers (Francia)

\section{Resumen}

La memoria, el recuerdo, el olvido son componentes esenciales de la novela Una belleza convulsa de J.

M. Fajardo. Nuestro objetivo es demostrar que en este texto se encuentra recogida toda la tipología de la memoria y las claves de su funcionamiento. La memoria es vida para el individuo y materia de la narración.

Palabras clave: memoria, escritura, secuestro, terrorismo.

\begin{abstract}
The memory, the oblivion are essential components of the novel Una belleza convulsa de J. M. Fajardo. Our aim is to demonstrate that in this text one finds quiet all the typology of the memory and the keys of his functioning. The memory is a life for the man and matter of the story.
\end{abstract}

Key words: memory, writing, kidnapping, terrorism.

$\Gamma$ zvetan Todorov (2007) caracteriza la literatura actual como formalista, solipsista y nihilista. El solipsismo se relaciona con la exploración narcisista

L del escritor que, de espaldas al mundo, se complace en estudiarse en las llamadas novelas del yo, cultivadas durante la última década especialmente en las letras francesas (Forest, 2007). Allí el artista se ficcionaliza y explora los límites de la creación artística cortándose del mundo común del lector. Este solipsismo ha contaminado incluso el género de la biografía. En las última décadas han visto la luz biografías en las que las dudas, las hipótesis y el mundo interior del autor de la biografía desplazan la reconstrucción objetiva de la vida del autobiografiado (Viart,

\footnotetext{
${ }^{1}$ Université d’Angers. Correo-e: dmiton49@free.fr. Recibido: 08-12-2008.
} 
2001). Igualmente, la novela histórica de los últimos treinta años en España ha usado con profusión la narración autobiográfica.

Que el yo está de moda parece obvio. El yo aparece también en la novela que nos disponemos a analizar. Pero éste es un yo que hunde sus raíces en la tradición de la autobiografía ficticia de la picaresca y que está emparentado también con una serie de relatos en primera persona que tratan igualmente el tema del terrorismo. En esos relatos se presenta la introspección de un terrorista que cuestiona la efectividad del crimen político y del terrorismo como opción vital (Alonso Rey, 2007).

En esta novela, el yo ficticio es un hombre de letras secuestrado por la banda terrorista ETA que emprende su introspección durante su cautiverio y después en libertad. La complejidad formal es patente: tres tiempos se congregan y dos escritos se imbrican. Pero, pese al formalismo y a la exploración del yo del protagonista -escritor fracasado-, esta novela está lejos del nihilismo que ofrece una visión incuestionablemente sombría de la naturaleza humana. Si bien se describe el nihilismo al que responde el terrorismo, la historia del antiguo secuestrado es una afirmación positiva de la fortaleza humana y del poder de la libertad.

Si, según T. Todorov, la literatura debe servir al conocimiento de lo humano, esta novela efectivamente lo consigue. No sólo en lo que respecta al terrorismo y a la tortura que supone un secuestro (Sarabia Heydrich, 1986), tan presentes en la vida política española, sino también por lo que respecta a los mecanismos de la memoria.

La memoria es también un tema de actualidad tanto en el ámbito político devoir de mémoire en Francia, ley de memoria histórica en España- como en el literario: libros de memorias, testimonios, ficciones que giran en torno a la memoria, por ejemplo El séptimo velo de Juan Manuel de Prada... Una belleza convulsa de J. M. Fajardo puede caracterizarse, entre otras muchas cosas, como un acto de memoria, definido así:

un viaje mental en el tiempo [que] pone de relieve algo admirable: al recordar, podemos liberarnos de las obligaciones inmediatas a la vez temporales y espaciales para revivir el pasado y proyectarnos en el futuro a nuestro gusto (Scacter, 1999: 33-34). 
En esta ficción autobiográfica, la rememoración de las vivencias del secuestrado se presentan como periplo mental: "un viaje al infierno en medio de la tranquilidad que reinaba en la casa". La mitificación del espacio es consecuencia de asimilar el secuestro a un rapto mítico, definido por los psicoanalistas como "un desplazamiento provocado [por un dios o un humano] que envía al individuo al otro mundo" (Boccara, 2004: 172).

De ahí que el zulo sea su infierno, los secuestradores sus demonios y él un muerto viviente. El tiempo también está mitificado y se le califica de invención demoníaca tanto por la vivencia mítica del secuestro, que entraña la metamorfosis del sujeto, como por los tiempos que convoca la narración de la experiencia.

La creación artística permite crear un espacio de transición entre el más allá y el aquí, entre el pasado y el presente² (Boccara ,2004: 175). El presente de la escritura se ubica en Paris dos años después de la liberación y el objetivo de la narración es dar testimonio de la experiencia del secuestro, es decir, del sufrimiento provocado por la tortura, de sus estrategias de supervivencia, de su búsqueda interior: "Quiero dejar memoria de los días que no fueron, recuerdo del tiempo robado y del torbellino de emociones que agitó aquellas jornadas sin sol ni noche".

Memoria y narración van juntas. La forma más compleja de la memoria es la narración de sucesos y de hechos, así "la escritura es un fenómeno de memoria [...] y el recuerdo es una construcción literaria" (Tadié, 1999: 135).

A pesar de las cuatro unidades que constituyen el eje de la historia - rapto, adaptación al espacio, liberación e identificación del secuestrador-, la narración está construida de forma circular: comienza y acaba en el presente de la escritura con el mismo incipit. El narrador, que narra en el presente el recuerdo de su secuestro

\footnotetext{
2 Bertrand MEHEUST: " raconter signifie parler ici et maintenant, avec une autorité fondée sur le fait que l'on s'est trouvé (littéralement ou métaphoriquement) là-bas à un autre moment " (Boccara, 2004: 221).
} 
pasado, recuerda que recordaba y lo que recordaba ${ }^{3}$. Estamos ante lo que sería une mise en abîme de la memoria que comporta el recuerdo de la agresión - el rapto- y lo recordado durante todo el periodo del secuestro (Alonso Rey, 2008).

La memoria se constituye mediante la adquisición de recuerdos a lo largo de toda la existencia. Los científicos han descrito las actividades neuronales que intervienen en la adquisición de recuerdos. Pero discrepan sobre el funcionamiento de la memoria. Para unos, esta no es más que un simple almacén de datos y el recuerdo su mera recuperación. Para otros, es un mecanismo sumamente complejo, capaz de recrear experiencias pasadas (Tadié, 1999: 99). La obra de Marcel Proust A la recherche du temps perdu mostró que la esencia de la memoria se encuentra en la conjunción entre el pasado y el presente para que resurja el recuerdo (Scacter , 1999: 44). En $U B C$ tres tiempos se entrecruzan: el presente de la escritura, el pasado del secuestro en el zulo y el pasado de la vida anterior en libertad.

Nuestro propósito es analizar la complejidad de la interacción de estos tres tiempos así como los tipos de memoria presentes en esta obra.

\section{La memoria afectiva y la memorización del contexto}

La memoria afectiva no sólo retiene involuntariamente las experiencias que por su fuerza se imprimen en la memoria de por vida, sino también el contexto en el que, por estímulo afectivo, se adquiere un recuerdo (Tadié, 1999: 117). Indudablemente un secuestro prolongado es una agresión de una carga emocional tan intensa que se transforma en recuerdo a largo plazo. Por eso, dos años después de su liberación, el protagonista emprende su narración minuciosa. Por lo mismo, el tiempo que precede al secuestro se convierte en decorado general del que destacan detalles que, en circunstancias normales, hubieran pasado desapercibidos por su cotidianeidad. Lo más sorprendente y característico de este tipo de memoria es la nitidez de los objetos y acontecimientos recordados. Y así lo consigna el narrador de

\footnotetext{
${ }^{3}$ Sobre los juegos con el tiempo, el tiempo del contar y el tiempo contado, ver Paul RICOEUR, (1984).
} 
la novela: "Recordaba con una precisión enfermiza hasta los más pequeños detalles de mis últimos días de vida. Cada frase, cada gesto".

La prueba de la intensidad y de la precisión de lo recordado la aporta la reproducción textual del inicio de su traducción:

[recordaba] Incluso las frases literales del inicio del texto - 'Míster Bones sabía que Willy no iba a durar mucho. Tenía aquella tos desde hacía más de seis meses y ya no había ni puñetera posibilidad de que se le quitara'

Se trata de frases retenidas en la memoria involuntariamente, es decir, no se deben a la memorización voluntaria mediante repetición o asociación nemotécnica. De ahí su valor probatorio como muestra de la amplitud del traumatismo.

La narración del rapto se realiza dos veces. La primera es sumamente esquemática. Se destaca el dónde, el cómo y el quién, como si el protagonista fuera un espectador que contemplara la escena viéndose a sí mismo en el papel de actor de ésta:

Me secuestraron al salir de mi casa, un día como cualquier otro. [...] Me sujetaron entre dos y me pincharon en el cuello y todo se volvió turbio y confuso. Hubo ruido de puertas y el ronroneo del motor de un coche y mucho movimiento.

Aparece al principio de la narración autobiográfica tras la exposición del motivo y del objetivo de ésta. Este resumen muestra cuál es el asunto y que éste comienza in medias res. No se trata de una autobiografía ordenada cronológicamente desde el nacimiento, sino que, a partir de un pasado, se evocan episodios autobiográficos narrados en el orden de su evocación. La segunda narración del rapto es minuciosa y precisa. La escena respeta la perspectiva del yo narrativo que se limita a reproducir percepciones y sensaciones no como un espectador exterior sino siempre como sujeto que vive la acción y que está inmerso en ella: "sentí un empujón; sentí el picotazo de una aguja; sentí unos brazos que me tomaban bajo los hombros; oí el golpe seco; todo se volvía borroso; mi cuerpo se había vuelto liviano"

La percepción del suceso no es global, sino parcial, por eso predomina lo fragmentario, la focalización restringida: "unas manos me doblaron el brazo; ante 
mis ojos se abría el estrecho paso que conducía hacia el jardín; una voz me ordenó...; había dos cabezas por encima de la mía, pero no parecían tener cara"

La percepción intelectual también lo es, de ahí que el narrador formule hipótesis: "tenían que ser más de uno porque me sentía inmovilizado". La pérdida de la consciencia provocada por la sustancia inyectada se manifiesta mediante la falta de conciencia del cuerpo - "flotaba en el aire" - y con la perturbación de la memoria inmediata: "No podía recordar dónde las tenía [las llaves]".

Esta segunda narración es importante porque el hecho que desencadena el recuerdo del rapto es precisamente otro recuerdo - "había quedado al mediodía con Antxon en el café Iruña de Bilbao. Íbamos a comer juntos" - al que accede laboriosamente tras vencer una amnesia pasajera. El secuestrado está en su camastro entre la vigilia y el sueño, entre su presente y el pasado del día del rapto: "los sueños corrieron como siempre a esconderse tras la cortina del olvido, pero llevándose esta vez también la memoria de mi condición".

¿Cómo narra la confusión e intersección de tiempos y el olvido? En primer lugar mediante oraciones que se pueden aplicar tanto al pasado narrado -el despertar en el camastro del zulo- como al despertar en su cama el día del secuestro. En un primer momento, este tipo de oraciones aseguran con su ambivalencia la confusión temporal: "Tenía la sensación de haber dormido demasiado. Se me había hecho tarde".

Posteriormente narra la discordancia existente entre sus actos y su actividad mental. Las acciones del despertar en el zulo - "seguía con los ojos cerrados [...] me removí, [...] entreabrí los ojos y la luz entró, [...] volví a cerrarlos [...] me incorporé" son similares a las que podría haber realizado en su casa y son comunes a los dos espacios y a los dos tiempos. Las explica mediante hipótesis basadas en gestos cotidianos cuya repetición instaura los llamados hábitos. Estos forman un conjunto de recuerdos que fundamentan las actividades mentales de los humanos y que constituyen una forma implícita de la memoria (Tadié, 1999:154): 
podía llamar por teléfono, [...] me había dejado la lámpara encendida, $[\ldots]$ me incorporé buscando a ciegas la segunda almohada, pero mi brazo no halló más que vacío, [...] la cama parecía haber menguado, faltaba el recuadro de la ventana de mi dormitorio.

Son hipótesis, basadas en los hábitos de su vida cotidiana en libertad, con las que explica las acciones realizadas en el zulo, imposibles en tal espacio. Sale del olvido cuando percepción física y mental coinciden: "las fotografías de un cartel turístico del país Vasco [...] y el olor a cerrado y a humedad vinieron a recordarme que no me hallaba en mi casa".

De este modo toda la narración minuciosa del rapto aparece como un acto de memoria involuntaria, consecuencia de un encadenamiento de recuerdos, asociaciones y olvidos.

Pero la memoria afectiva es también la que hace sentir una impresión o una sensación cuando se evoca un recuerdo. El recuerdo desencadena una reacción emotiva en el momento en el que resurge (Tadié, 1999:177). Esa nueva emoción puede hacer sufrir. Así ocurre cuando rememora su vida con Eva, su ex-pareja. La evocación provoca, al comienzo y al final, sendas sensaciones negativas que inciden en el momento del recuerdo. Narrativamente, sirven de marco para acotar los límites de este episodio biográfico. Dicha evocación comienza con la descripción de un dolor sentido físicamente y acaba con un sentimiento de tristeza. La violencia del dolor penetrante es simultánea a la aparición del recuerdo:

sentí una punzada en la boca del estómago cuando el rostro de Eva se dibujó en mi memoria [...] el punzón que parecía escarbar mi estómago se hundió con renovado brío y pensé incluso en detener mi patético paseo, pero la realidad hostil de mi tumba me animó a continuar la marcha.

Acepta el dolor físico para evitar su presente de secuestrado, en cambio erradica el sentimiento de tristeza final poniendo fin a la evocación para proteger su equilibrio emocional:

y probablemente había llegado el momento de dejar de recordar aquel amor pasado. [...] evocarlo ahora sólo servía para llenarme de tristeza. Y eso era lo último que necesitaba en mi cautiverio. 
El dolor lo revigoriza y en cambio la tristeza aminora su fuerza para soportar el cautiverio. Las sensaciones que provocan los recuerdos inciden en su estado anímico y en su capacidad de resistencia para afrontar la tortura a la que se ve sometido.

Evocar una emoción pasada no provoca automáticamente la misma reacción emocional. San Agustín explicaba que podía recordar un hecho triste o alegre sin sentir ni tristeza ni alegría (Tadié, 1999: 34). A veces por contigüidad se siente una emoción similar a la del momento evocado. Esto ocurre en nuestro relato cuando el narrador evoca el sentimiento de tristeza que experimentó un día ante la contemplación del paisaje del valle de Cuartango. Por contigüidad, siente una tristeza similar, pero no es la de aquella mañana ante el valle, es una tristeza del presente, fruto de su condición de cautivo:

Una punzada de tristeza me distrajo de la contemplación del valle, la misma que se repetía ahora durante el nuevo paseo que había emprendido en las soledades de mi tumba, mientras canturreaba : un kilómetro a pie es poco, es poco para mí.

\section{La memoria afectiva y sensitiva}

La memoria afectiva hace sentir en el presente la emoción sentida en el pasado. El recuerdo de un hecho conduce a recrear mediante la imaginación la emoción que se sintió en el pasado. Esa emoción recreada en el momento de la evocación no es exactamente la misma del pasado, pues la personalidad del individuo y su realidad han cambiado. Se trata de un recuerdo imaginario (Tadié, 1999: 185). Se habla de memoria sensitiva cuando la sensación sentida en el pasado invade al sujeto (Tadié, 1999: 189). Este tipo de memoria está bien representado en esta novela. En el presente de la escritura, el narrador tiene en sus manos el cuaderno donde escribía en su cautiverio. La aspereza de su tacto provoca la reactualización de emociones y sensaciones pasadas. Es el tipo de memoria que Proust llamaba involuntaria: "Vuelvo a sentirlo en mi mano y todos los miedos, toda la angustia, todo el horror de aquel tiempo resurgen como si aún me encontrara enterrado vivo". 
En ese momento no describe ni analiza esas sensaciones que sí están analizadas en otros momentos del relato, sino que teoriza sobre la memoria como sexto sentido, el del recuerdo emocional (Tadié, 1999: 196): "los sentidos tienen una memoria que nos supera y un olor y un sabor, un roce que nos devuelven al pasado con la vehemencia invasora de las sensaciones".

El objeto -cuaderno- y las sensaciones que reaviva se convierten en la clave de acceso al pasado y en el punto de partida del viaje interior $\mathrm{y}$, por ende, de toda la narración. De esta manera, dos tipos de memoria se asignan a dos momentos. En libertad, el recuerdo surge gracias a la memoria sensitiva, involuntaria, y en cautividad gracias a la memoria voluntaria.

\section{El recuerdo voluntario}

La memoria se expresa mediante el recuerdo que surge por un acto de voluntad. El recuerdo puede adquirirse voluntariamente para restituirlo en un plazo corto, como es la memorización de un número de teléfono, o medio, como es la lección de un escolar. Para fijar el recuerdo se usan formas de memoria como la repetitiva, auditiva, visual o lógica (Tadié, 1999: 123). Pero el recuerdo también puede ser adquirido involuntariamente y reactualizado voluntariamente. Es el caso del episodio de la escritura en el cuaderno. Para colmar su tiempo vacío, el secuestrado decide escribir en un cuaderno amarillo la historia de los demonios con los que solía ilustrar los cuadros su profesor de historia del arte, el padre Otaegui, un hombre en conflicto entre sus obligaciones y sus pasiones carnales. Si bien el nombre y las historias de aquellos demonios no fueron nunca objeto de una memorización sistemática, sino que fueron calando a base de repeticiones habituales, el recordarlos para escribir es un acto voluntario, no exento de dificultad, conseguido gracias a una concentración intensa:

Me pasaba horas sentado delante del cajón, con la mirada fija en el cuadernillo, como si las páginas en blanco fueran ventanas que me permitieran asomarme al pasado. Me esforzaba en recordar los raros nombres diabólicos... 
Para hacer surgir el recuerdo, se suelen usar soportes exteriores: fotos, calendarios, escritos, testimonios de otras personas, visitas a lugares y paisajes de otras épocas... La reconstrucción del pasado a partir de ellos ha sido un tema literario frecuente cuyo objetivo era salvar un pasado de la nada del olvido. Pero en el caso de la persona secuestrada, el hecho de recordar es de vital importancia. El sujeto, desposeído de toda referencia, atemorizado, amenazado, cosificado, sólo cuenta con su memoria como prueba de su identidad.

En esta novela, el recuerdo voluntario es el arma con que cuenta el secuestrado para hacer frente a su presente. La memoria se convierte en el antídoto de la locura, en una estrategia para sobrevivir: "aquel paseo por el territorio de la memoria era el único asidero de mi cordura [...] que me permitía salvar los abismos en que amenazaba hundirme mi infierno".

Para mantener la cordura, el secuestrado asocia la disciplina física -caminar en el zulo- a la mental: recordar voluntariamente apoyándose en estímulos. El texto final cuenta con trece unidades: seis paseos (capítulos pares), seis unidades en el infierno (capítulos impares) y la última titulada En el bosque. Las unidades tituladas Paseos remiten al pasado en libertad mientras que las que se titulan Infierno remiten a su pasado de secuestrado. Los estímulos que propician el recuerdo son de dos tipos: materiales e inmateriales. Por toda decoración, en el zulo existe un póster turístico con tres fotos. Una de ellas representaba un lugar conocido cuya familiaridad activa el recuerdo y ritma el primer paseo: "Leí el pie de la foto: Salinas de Araña Y el recuerdo acudió presto a mi memoria. La primera y única vez que había visto aquellas salinas yo iba vestido de soldado".

Estamos ante una variante del tema romántico de la vuelta al paisaje del pasado feliz. El estímulo material que desencadena el tercer paseo es el libro Cien años de soledad, asociado mentalmente a otra novela del mismo autor El general en su laberinto, y a su lectura durante un viaje de las Vascongadas a Madrid. Los otros estímulos propiciadores de recuerdos son inmateriales. El segundo paseo se origina al interrogarse sobre las sensaciones que experimenta durante su estancia en el zulo. 
Busca un equivalente similar en el pasado, pero para obtenerlo ahora no se sume en un estado de concentración forzoso, sino que voluntad y azar harán surgir el recuerdo por contigüidad. El camino que despeja la memoria es la materia que reviste las paredes:

¿Cuándo y dónde había conocido con anterioridad mi infierno? Sabía que estaba a punto de conseguirlo, sólo necesitaba no obcecarme, dejar que mi mente vagara libremente y permanecer al acecho. El recuerdo vendría solo. [...] El secreto estaba, precisamente, en sus paredes.

Los recuerdos que ocupan el cuarto y el sexto paseo surgen de obligarse a recordar voluntariamente sensaciones similares a las vividas en el zulo. Así, el tiempo de espera que se abre ante él después de que el secuestrador le confisque el cuaderno amarillo le lleva a recordar otro tiempo de espera: el que se abrió ante él cuando dejó a Eva, su pareja. La muerte con la que le amenaza el secuestrador le conduce a otros terroristas y a otras muertes; despierta en él la narración de la amistad y de un viaje con un ex-terrorista amigo suyo y, por ende, la historia de la banda ETA. La palabra de su secuestrador, generada tras la lectura del cuaderno amarillo, suscita nuevos recuerdos que acompañan el quinto paseo. Entre el tiempo en el zulo y el pasado en libertad se establece una continuidad y un paralelismo ensartados en lo autobiográfico que ayudan a conservar la conciencia del yo, a evitar la destrucción de la personalidad y a proteger la identidad (Sarabia Heydrich , 1986: 223).

Esto estímulos originan una cascada de recuerdos encadenados que dan lugar a un artificio temporal nada desdeñable. Como muestra, describimos el tercer paseo. El secuestrado, con el libro Cien años de Soledad en la mano, se recuerda con un ejemplar de El general en su laberinto, del mismo autor, en el andén de una estación de tren. En ese momento se proyectaba al futuro próximo - estar ya en el tren- y se imaginaba en él. Después retorna al pasado inmediato - preparación del viaje-. Hace un paréntesis y vuelve al momento del secuestro en el que contempla Cien años de soledad en el zulo. Tras el inciso retoma la espera del tren que, a su vez, le recuerda otra espera, otra estación relacionada con el padre de Eva. La figura del padre le lleva 
a analizar su sentimiento de culpabilidad porque iba a engañar a Eva con Lola. A continuación se adentra en su pasado y recuerda a Daniela y a otras mujeres con las que había sido infiel a Eva. Desde el presente de la escritura en París, el antiguo secuestrado enjuicia su pasado. Cuando finaliza, retoma el pasado del tren. Resume la novela que le hace recordar una excursión con Eva. Posteriormente, el tren que le llevaba a Madrid provoca el recuerdo de su infancia en la capital y la fuga con su hermano para escapar de las discusiones familiares debidas a las infidelidades paternas. Esas traiciones se equiparan con las suyas a Eva, anteriormente desmenuzadas.

Esta cascada de recuerdos fragmentarios muestra bien la discontinuidad característica de la memoria. Muestra igualmente cómo se actualizan los recuerdos almacenados en redes neuronales que a su vez desencadenan la reactivación de otras redes y otros recuerdos ligados a los anteriores por asociación de ideas, sensaciones, sentimientos. La imaginación, llamada reconstructiva, se encarga de establecer vínculos entre las diferentes redes neuronales, entre los diferentes recuerdos. De hecho, todo recuerdo es en parte imaginario (Tadié, 1999: 316).

Esta fragmentación biográfica, fruto de una búsqueda del recuerdo, sume al individuo en un viaje interior de efecto liberador. Si este efecto es similar a todas las búsquedas del pasado, en el caso de un hombre encerrado adquiere una dimensión de libertad insospechada. Así, por ejemplo, el recuerdo de la risa de sus compañeros de mili en el primer paseo le provoca a él carcajadas en el zulo en el momento de la evocación. El recuerdo modifica su realidad y en cierto modo la suspende o la anula temporalmente:

[...] aquel sonido que casi había olvidado me arrancó de los recuerdos del imaginario paseo y me devolvió a la realidad: cuatro paredes de madera [...] Durante aquella caminata, las fronteras de mi mundo se habían ensanchado hasta el horizonte y por sus dominios habían corrido ríos y rutas, soplado el viento y brillado las estrellas.

Se suele subrayar que la memoria es un espacio de libertad (Tadié, 1999: 330). El individuo en su presente, indisociable de su pasado, elige conservar en su memoria unos recuerdos determinados. Los recuerdos pueden obligar a actuar de 
una manera o de otra. En esa elección radica la libertad. En este relato el tiempo del secuestro se convierte en un tiempo de introspección - "mis pasos me conducían al interior de mí mismo" - que propicia la metamorfosis del individuo. El secuestrado da prioridad a los recuerdos relacionados con su vida afectiva y sexual - experiencias eróticas con la niñera, mujeres en su vida- figura de su padre mujeriego e infiel- un tipo de vida superado en el presente de la escritura transformado en un padre de familia y esposo ejemplar.

\section{El enjuiciamiento del pasado.}

Los recuerdos no son imágenes estáticas. Según Israel Rosenfild (1996: 106), los recuerdos se modifican en función del presente. A medida que el individuo envejece se forja una idea de sí que se refuerza eligiendo ciertos recuerdos, modificándolos o idealizándolos:

reescribimos la historia, revisamos nuestros juicios sobre nuestra propia experiencia reestructurando los pensamientos que hemos podido alimentar sobre personas o hechos pertenecientes a nuestro pasado (Rosenfild, 1996: 106)

La metamorfosis del yo, que entraña todo secuestro vivido como secuestro mítico, se pone de manifiesto en esta novela cuando el protagonista enjuicia su pasado a la luz de su presente de hombre libre y padre. La experiencia del secuestro le transforma moralmente. Le impide mentirse o no ser honrado consigo mismo:

Sería fácil, ahora, mientras escribo estas líneas, mientras evoco aquel paseo subterráneo [...] cargar las culpas sobre Eva [...] pero sería mentira y ya no me queda espacio en el corazón para más embustes

El análisis de sus infidelidades a Eva le hace percibir su yo pasado no sólo como el de un ser falso, irresponsable y cobarde - "hacía recaer sobre Eva la responsabilidad de verme obligado a habitar un mundo de mentiras" - , sino como un prisionero: "me sentía prisionero de mi propia vida, incapaz de librarme del falso personaje en que me había convertido". Frente a la mentira de la prisión de su vida con Eva, se yergue su vida de libertad y verdad actuales con su mujer; frente a la mentira que impide la escritura - "ni es posible la escritura en quien se miente a sí 
mismo" -, la verdad del presente de la narración de su secuestro; frente al rechazo a tener un hijo, su paternidad actual.

Paradójicamente, tras la rememoración de su pasado, tras su análisis de conciencia, la imagen que se desprende de su vida en libertad anterior al secuestro es la de una prisión: "arrastraba la culpa como un reo, condenado además a una soledad que desconocía y me aterraba [...] aquella que se siente en compañía".

La escritura del cuaderno en su cautiverio le sirve para conocerse, analizarse y explicarse, como medio para acceder a su verdad profunda. Esta verdad es el concebirse como producto de dos modelos masculinos presentes en su infancia. Por un lado el modelo de su maestro, el padre Otaegui, que reprime sus pulsiones sexuales y se culpabiliza por ellas y por otro lado el modelo paterno con sus continuas infidelidades que degradaban el ambiente afectivo del hogar infantil.

\section{El recuerdo difuso. La alteración del pasado.}

La precisión de los recuerdos se altera con el tiempo, pues la evolución de la personalidad modifica la percepción del pasado, tanto de los acontecimientos como del propio yo anterior (Tadié, 1999:134). En nuestro relato, el secuestrado narra con precisión en el cuaderno amarillo sus primeras experiencias eróticas: caricias íntimas a su niñera dormida. En cambio no puede precisar la duración exacta de sus viajes nocturnos a la habitación de la niñera. Junto a la impresión infantil se encuentra la explicación del adulto: "a mí me pareció una eternidad, pero siendo el tiempo de la infancia lento y caprichoso, bien pudiera haber sido apenas un par de semanas".

El acontecimiento mismo se explica desde la perspectiva del adulto dándole una interpretación insospechada en la inocencia de la infancia:

Ni la facilidad con que lograba acceder a los más recónditos dominios de su cuerpo, ni la manera en que se revolvía en la cama [...] me hicieron sospechar que pudiera ser un ladrón robado, que allí donde creía hurtar el secreto del placer fuera en realidad utilizado para propiciar uno[...] 
En la narración de sus aventuras no hay descripción física de la niñera. Esta se la exige el lector del cuaderno, su secuestrador. Exigencia que le hace enfrentarse a la experiencia del recuerdo irremediablemente perdido. Mediante la concentración y la voluntad parte a la conquista del rostro del pasado, pero la desfiguración infligida por el tiempo es irreversible. El rostro de la niñera es fantasmagórico, un espacio en blanco sobre el que proyecta las facciones de otras mujeres:

El verdadero rostro de Marisa se había perdido sin remedio en el hondonero de los años. Más que una persona concreta, ella era ya una sensación, un aroma, el tacto fugaz de una piel tras las cortinas $[\ldots]$ como si no guardara de ella más que el espacio vacío de su ausencia

\section{El recuerdo obsesivo y el recuerdo reprimido}

La voluntad posee un margen escaso en materia de memoria y de olvido. Hay recuerdos que voluntariamente se quieren olvidar pero, precisamente por ello, se recuerdan. Otras veces hay que esforzarse en no olvidar (Tadié, 1999:232). En esta novela, el protagonista se enfrenta en dos ocasiones al olvido voluntario. La primera tiene lugar tras la separación de Eva. Pese a ser provocada por él, su soledad afectiva se llena con recuerdos obsesivos de su vida común, cuyo efecto se compara con la adicción a las drogas, que le impiden proyectarse en el futuro: "Lo cierto era que su recuerdo se enredaba en todos mis pensamientos, como una zarza que me impidiera avanzar".

El olvido es ambivalente. Aunque es benéfico para poder reconstruirse y seguir viviendo, es maléfico cuando se convierte en cómplice del mal: "nadie quiere enfrentarse al horror, a nadie le complace recordarlo. Esa es siempre la ventaja del verdugo: sus obras son tan horribles que pronto caen en el olvido".

En cambio mantener la memoria del mal y evitar el olvido, individual y colectivamente, es imprescindible para sedimentar las bases del presente y del futuro. Así la figura del ex-terrorista Antxon se dignifica gracias a que mantiene vivos sus recuerdos: 
Sólo la memoria, $[\ldots]$ podía evitar que se convirtieran en algo banal. [...] porque el asesinato y la injusticia no eran caprichos de la Naturaleza [...] eran obra de hombres [...] Y Antxon tenía el valor de no olvidarlo.

Existe un amago de olvido que podríamos calificar de recuerdo evitado o reprimido. En esta novela, el protagonista descubre que recordar e intimar con su secuestrador se han convertido en estrategias más o menos voluntarias e inconscientes para postergar lo que no podía olvidar : "no eran más que maniobras de distracción, señuelos de la memoria o fantasías para alejar de mi conciencia aquello que no quería recordar".

El recuerdo postergado es la declaración de amor que hizo a su padre el día de su entierro. La da por escrito en su cuaderno de secuestro dejando libre curso a la escritura como si este automatismo lo liberase. En el cuaderno del secuestro da testimonio de los hechos mientras que en el texto final, redactado en el presente de la escritura, los analiza. No lo hizo antes para evitar que su lector-secuestrador conociera demasiado de su intimidad. La liberación que experimenta es consecuencia de la expresión de sus auténticos sentimientos, como ya le ocurrió en el momento de la ruptura con su pareja: "necesitaba decir en voz alta lo que no me había permitido decirme en el silencio de mi conciencia: que pese a las mentiras, las traiciones y las debilidades de mi padre yo le seguía queriendo".

El protagonista rescata del pasado los sentimientos de su infancia, como si estos estuvieran intactos a pesar de las desilusiones y traiciones posteriores y como si se impusieran, con vida propia, a su voluntad: "aquellas palabras [...] parecían nacer de un rincón de mí que en realidad estaba en otro cuerpo y en otro tiempo, en el cuerpo del niño que escuchaba a su padre leer...".

La disonancia que existe entre sus sentimientos infantiles y su conducta de adulto se manifiesta en la forma narrativa elegida. El narrador no asume la responsabilidad de sus sentimientos. En vez de usar la forma afirmativa, se aventura estableciendo hipótesis sobre lo que quizá no habría ocurrido si las circunstancias hubieran sido diferentes: 
Y [Lola, su amante] no vino. Quizá si lo hubiera hecho yo no me habría quedado junto a la tumba [...] ni habría dejado escapar dos lágrimas [...] quizá no habría dicho aquellas palabras inútiles...

$\mathrm{Su}$ responsabilidad se difumina y el origen de su declaración de amor se atribuye a las circunstancias, a lo aleatorio, no a lo esencial. Utiliza el mismo modo hipotético cuando analiza su comportamiento: "a lo mejor no era más que el ceremonial de un castigo, una humillación que me imponía a mi mismo ante la tumba de mi padre... ".

La liberación no viene acompañada de un sentimiento de plenitud o de felicidad sino de sentimientos de menosprecio de sí y de vergüenza. Estos se deben tanto a la naturaleza de sus sentimientos, existentes pese a la condena moral de su padre que le había llevado a cortar toda relación con él, como al hecho de considerarse su remedo y heredero: "Diez años de separación y rencor para terminar reconociendo en mí los mismos pecados que tanto me había costado perdonarle".

Ya hemos señalado anteriormente los vínculos entre memoria e imaginación. La imaginación constructiva se apoya en los recuerdos para lanzarse hacia lo desconocido. El cúmulo de recuerdos forma la base de la creación, esto es, de la imaginación (Tadié, 1999: 318). Ejemplo de ello es la propia creación del narrador ficticio de esta novela quien, basándose en sus recuerdos de secuestrado, elabora el texto que el lector tiene entre las manos. Pero nos interesa subrayar el vínculo entre recuerdo e imaginación en el episodio en el que se produce una nueva identificación entre padre e hijo. El secuestrado se descubre unido a su padre también en la muerte. En el zulo, él se considera un muerto en vida de la misma manera que su padre es un muerto en la muerte. La identificación se logra en primer lugar a partir del recuerdo del padre en el féretro y después dando paso a la imaginación. Primero parte de las similares condiciones materiales en las que se encuentran - silencio, humedad, interior del féretro, descomposición del cuerpo- para llegar, posteriormente, a la acción - excavación de un túnel- con el fin de rescatar y salvar a su padre :

Imaginé que ése sería también el silencio que reinaría en la oscura tumba donde yacía mi padre. [...] Imaginé que alargaba el brazo derecho y que comenzaba a escarbar con las uñas... 
De esta forma tan sutil se introduce otro tema relacionado con el más allá: el descenso a los infiernos por amor. En este pasaje no sólo se vislumbra el mito de Orfeo sino que hasta se oye el eco de los versos de Miguel Hernández en su Elegía a Ramón Sijé: "quiero escarbar la tierra con los dientes/ [...]/quiero minar la tierra hasta encontrarte".

\section{El recuerdo suspendido}

El olvido puede ser parcial o temporal. La memoria acumula recuerdos que se reactualizan y toman sentido cuando existe la clave que desvela su significación. Es lo que ocurre en esta novela cuando el protagonista identifica a su secuestrador. Toda una red de recuerdos y de asociaciones se activan para encontrar el rostro y el nombre del encapuchado que lo custodiaba durante el secuestro. Durante una visita a un barco conoció a un cocinero con una experiencia amorosa fracasada: "a mí el matrimonio me ha durado lo que un embarazo, porque estuve casi ocho meses fuera y fue nacer el crío y separarnos".

Una variante de esta frase fue pronunciada por su secuestrador un día que jugaban a las cartas: "el amor les dura lo que el embarazo, te sacan lo que quieren y si te he visto no me acuerdo". Ni en ese momento ni durante el resto del secuestro, el cautivo reactivó su recuerdo poniéndolas en relación. Permanecen en un estado de olvido latente que despierta del letargo cuando, ya libre, repite inconscientemente esa misma frase: "me dije que mi demonio estaba equivocado que el amor no era un robo [...] que el de mi mujer duraba ya más que su embarazo".

A partir del momento en que es consciente de que hace un calco de la frase, emprende una búsqueda voluntaria de indicios para ubicarla: la voz del secuestrador, las barcas del Sena que reactualizan el recuerdo del barco, el recuerdo del olor del marmitako en su celda que le conduce a la conversación sobre la desaparición de ese plato en los menús actuales del barco. Cuando toda esa red de indicios forma un conjunto coherente, la identidad del secuestrador se desvela: Aitor, el cocinero. La capucha que lo despersonalizaba cae con el recuerdo de su rostro. Un 
recuerdo que opera en el ex-secuestrado una nueva metamorfosis. Se concibe ahora como hombre libre de miedo mientras que la imagen de prisionero se la adjudica a su antiguo verdugo: "prisionero de su propia cobardía, de su incapacidad para romper las cuerdas que le ataban al pesado fardo de odio que le retenía en las tinieblas"

Para concluir recordaremos la frase de Saul Bellow en The Bellarosa Connection: "La memoria es la vida". Efectivamente la memoria construye la identidad personal y asegura el vínculo entre el mundo exterior, el pasado del individuo, su mundo interior y su presente. Esta definición adquiere total sentido para el muerto viviente protagonista de esta narración. Pues, con el propósito de conservar la cordura, de no ceder a la locura, de dar sentido al tiempo vacío, el secuestrado se impone el recuerdo como disciplina junto con el caminar. Ya libre, vuelve a recordar para dejar constancia de su pasado y para deshacerse de su miedo. Efectivamente, para este secuestrado de ficción, la memoria es vida, salud y liberación junto con la escritura. Pero la memoria no es monolítica. Existen diversos tipos de memoria: la implícita, la inmediata, la biográfica, la afectiva, la sensitiva, la voluntaria...El recuerdo se altera, se difumina, queda suspendido, se pierde definitivamente, se vuelve obsesivo... Todos estos aspectos del olvido, de la memoria y de su funcionamiento aparecen en esta novela que puede ser considerada como un tratado del arte de la memoria.

\section{BIBLIOGRAFÍA}

Alonso Rey, Ma D. (2008): «Enlèvement: narrateurs et lecteurs », Colloque Récits de prison et enfermement, Universidad de Angers, junio 2008, en prensa.

Alonso Rey, M ${ }^{\mathrm{a}}$ D. (2007): “ La imagen del terrorista en la novela española actual », Lectura y signo, 2: 325-354.

Boccara, M. (2004): « L'enlèvement au cœur du mythe » in Markos Zafiropoulos, Michel Boccara, Le mythe: pratiques, récits, théories. Vol. 4: Anthropologie et psychanalyse, Paris, Economica, Anthropos.

Forest, P. (2007): Le roman, le réel et autres easais, Nantes, éditions Cécile Défaut.

Genette, G. (1972): Figures III, Paris, Editions du Seuil.

Ricoeur, P. $(1983,84,85)$ Temps et récit, 3 Tomos, Paris, Editions du Seuil. 
Rosenfield, I. (1996): Une anatomie de la conscience, Paris, Flammarion.

Sarabia Heydrich, B. (1986): «El secuestro como tortura », Escritos sobre la tolerancia: homenaje a Enrique Casas, Editorial Pablo Iglesias.

Scacter, D. L. (1999): A la recherche de la mémoire, Paris, Bruxelles, Boeck Université.

Tadié, J-Y § M. (1999): Le sens de la mémoire, Paris Gallimard.

Todorov, T. (2007): La littérature en péril, Flammarion, Café Voltaire.

Viart, D. (2001): «L'imagination biographique dans la littérature française des années 1980-1990» in Actas del coloquio L'eclatement des genres, Marc Dambre et Monique Gosselin (ed), Presses Universitaires de Paris 3. 